\title{
Atmospheric Pressure Plasma Treatment and Following Aging Effect of Chromium Surfaces
}

\author{
Vadym Prysiazhnyi \\ Department of Physical Electronics, Faculty of Science, Masaryk University, Brno, Czech Republic. \\ Email:mr.vodik@gmail.com
}

Received December $6^{\text {th }}, 2012$; revised March $10^{\text {th }}, 2013$; accepted April $10^{\text {th }}, 2013$

Copyright (C) 2013 Vadym Prysiazhnyi. This is an open access article distributed under the Creative Commons Attribution License, which permits unrestricted use, distribution, and reproduction in any medium, provided the original work is properly cited.

\begin{abstract}
The results of atmospheric pressure plasma treatments using diffuse coplanar surface barrier discharge (type of surface dielectric barrier discharge) on chromium surfaces are reported. A significant increase of surface wettability was observed after short plasma exposition. A quantitative value of surface wettability, i.e. the surface free energy, changed from $29 \mathrm{~mJ} / \mathrm{m}^{2}$ to over $80 \mathrm{~mJ} / \mathrm{m}^{2}$. In time, a hydrophobic recovery of the plasma treated surfaces was observed. Careful study by surface free energy measurements and x-ray photoelectron spectroscopy was performed to be able explaining the effects of plasma treatment. Studied samples were treated in air, oxygen and nitrogen plasma and aged in air and vacuum. Main reasons for increased wettability and aging effect are surface cleaning and transformations in chromium oxide. Additionally, generation of surface nitrate groups was found on the chromium surface as a result of plasma treatment in humid air.
\end{abstract}

Keywords: Chromium Surface; Plasma Treatment; DCSBD; Aging Effect; Atmospheric Pressure Plasmas

\section{Introduction}

Nowadays many atmospheric pressure non-thermal plasma sources have been developed for surface modifications [1-3]. This type of plasma has the many merits compared to chemical treatments or low-pressure plasma treatments, e.g. low maintenance and running costs, short processing time and absence of toxic wastes or byproducts. The use of atmospheric pressure plasma is intensively studied for polymer surfaces [4], textiles [5] or plastics [6], when surface modifications are necessary to overcome certain technologic issues of materials, like low surface wettability or low adhesion. Comparing the number of research done on polymer surfaces, plasma treatment of metallic substrates was studied less intensively, but still a lot of work has been done on the topic $[7,8]$.

A large number of published papers, where the plasma treatment is involved, is dedicated to study of metal surface cleaning and activation $[9,10]$. It means the plasma is used to prepare the surface prior to further processing, like coating, painting or bonding. If no coatings are deposited while plasma applied to sample surface, the treatment often has non-permanent character. It is said that surface exhibit the aging effect [11]. Typical pa- rameter for surface pretreatment efficiency is wettability, evaluated by the contact angles or surface free energy (SFE) measurements. In most cases the surface free energy is increasing as a result of the surface pretreatment using atmospheric pressure air plasma [12]. Aging effect can be defined as a decrease of the SFE (or hydrophobic recovery) after several hours or days [13]. It may play an important role when a time delay between technological steps is necessary. Opposite to lots of experimental and modeling results regarding the aging effect of plasma treated polymer surfaces that are presented in literature $[13,14]$, it is still not well studied for metallic surfaces. In some works the aging effect was measured [15], but explanations of its reasons were not presented.

When plasma treatment is done in air at atmospheric pressure, the influence of humidity on the treatment efficiency should be taken into careful account. The plasma chemistry of humid air for the dielectric barrier discharges (DBDs) was studied in detail by few research groups $[16,17]$. Note that in humid air plasma the $-\mathrm{NO}_{\mathrm{x}}$ radicals are generated in plasma volume (as an intermediate products).

In this paper the effects of chromium surface after the plasma treatment is described. Chromium surface was chosen as an object of study because of two main reasons: 
high use of chromium for anticorrosion coatings/adhesive interlayers and the use of chromium in major aluminium and steel alloys. Even though the chromization process is one to be replaced nowadays, it is still widely used. We are not aware of any paper studying the plasma treatment of chromium substrates. Main motivation of current research was fundamental research on the topic of interactions between atmospheric pressure cold plasmas and metallic surfaces. In this paper you will find the explanation of the wettability increase after the plasma treatments, reasons of the aging effect of plasma treated chromium surfaces, hydrophilic recovery of surface wettability after immersion of the plasma treated surfaces in deionized water and the influence of air humidity.

\section{Materials and Methods}

\subsection{Samples}

Chromium samples were prepared by electrochemical chromization procedure on nickel substrates $(1 \mathrm{~mm}$ thick sheets) using GLAZCHROMBAD DC-150 (Dr. Max Schlotter) provided by SVAZIKO (Czech Republic). Layer thickness was $20 \mu \mathrm{m}$. The samples were cut with size $10 \mathrm{~cm} \times 3 \mathrm{~cm}$ for the surface free energy measurements and $1 \mathrm{~cm} \times 1 \mathrm{~cm}$ for the $\mathrm{x}$-ray photoelectron spectroscopy (XPS) measurements. Prior to plasma treatments and surface analysis all the samples were cleaned as follows. First, wet tissue was used to remove metal dust particles. Then the samples were cleaned in ultrasonic bath for $5 \mathrm{~min}$ in isopropanol, dried, cleaned in ultrasonic bath for $5 \mathrm{~min}$ in acetone. After chemical cleaning the samples were dried with flow of compressed air and stored at least one day in ambient air before the plasma treatments.

\subsection{Plasma Treatment}

The diffuse coplanar surface barrier discharge (DCSBD) source was used for chromium surface treatments [18]. This plasma source produces thin plasma layer (about 0.5 $\mathrm{mm}$ ) of cold plasma. It was chosen for the surface treatments due to its specific geometry that allows obtaining higher power densities than in typical volume DBD reactors as well as its geometry allows treating large flat surfaces. The coplanar electrode was produced on the alumina ceramics that have size $26 \mathrm{~cm} \times 9.3 \mathrm{~cm}$. Silver metal electrodes were evaporated on the bottom side in etched channels $1.5 \mathrm{~mm}$ wide with $1 \mathrm{~mm}$ distance in between them. To cover the area of $20 \mathrm{~cm} \times 8 \mathrm{~cm}$, thirty eight metal stripes in comb-in-comb structure were produced [19].

The surface treatments were done at atmospheric pressure and room temperature by moving the sample above the DCSBD electrode with a constant speed. Dry, ambient and humid air, nitrogen and oxygen were used as a plasma gas. The humidity of air was set from less than $2 \% \mathrm{RH}$ to more than $90 \% \mathrm{RH}$ and controlled by Extech RH520A. The plasma treatment time was $5 \mathrm{~s}, 40$ $\mathrm{s}$ and $100 \mathrm{~s}$. The distance between the sample and the DCSBD electrode was set to $0.35 \mathrm{~mm}$. The applied power, which was measured by Energy Check 3000 (Voltcraft, Germany), was set to $340 \mathrm{~W}$ (the power density of $1.9 \mathrm{~W} / \mathrm{cm}^{2}$ ). A scheme of the experimental setup is shown in Figure 1.

\subsection{Surface Diagnostics}

Surface wettability was estimated by a sessile-drop technique, measuring the static contact angles of few test liquids with well-defined properties (i.e. surface tension $\sigma_{1}$ and its polar $\sigma_{1}^{\text {polar }}$ and dispersive $\sigma_{1}^{\text {disp }}$ components). The values of contact angles were measured using Surface Energy Evaluation System (Advex Instruments, Czech Republic). For current measurements three test liquids were used. They are distilled water $\left(\sigma_{1}=72.6\right.$ $\left.\mathrm{mJ} / \mathrm{m}^{2} ; \sigma_{\mathrm{l}}^{\text {polar }}=21.6 \mathrm{~mJ} / \mathrm{m}^{2} ; \sigma_{1}^{\text {disp }}=51 \mathrm{~mJ} / \mathrm{m}^{2}\right)$, dimethyl sulfoxide (DMSO; $\sigma_{1}=44 \mathrm{~mJ} / \mathrm{m}^{2} ; \sigma_{1}^{\text {polar }}=36 \mathrm{~mJ} / \mathrm{m}^{2} ; \sigma_{1}^{\text {disp }}$ $=8 \mathrm{~mJ} / \mathrm{m}^{2}$ ) and $50 \%$ solution of $\mathrm{K}_{2} \mathrm{CO}_{3}$ in deionized water $\left(\sigma_{1}=103.8 \mathrm{~mJ} / \mathrm{m}^{2} ; \sigma_{1}^{\text {polar }}=34 \mathrm{~mJ} / \mathrm{m}^{2} ; \sigma_{1}^{\text {disp }}=69.8\right.$ $\mathrm{mJ} / \mathrm{m}^{2}$ ) [20,21]. The volume of each drop was $2 \mu \mathrm{l}$ and the average value of at least 6 drops was calculated for each test liquid on each sample. To recalculate the surface free energy the Owen-Wendt regression model [22] was used.

The x-ray photoelectron spectroscopy (XPS) measurements were performed on Omicron Nanotechnology ESCAProbeP spectrometer equipped with a hemispherical analyzer operated in FAT mode (Phoibos 100 from company Specs). The $\mathrm{Al} \mathrm{K}_{\text {alpha }} \mathrm{X}$-ray source $(1486.7 \mathrm{eV})$

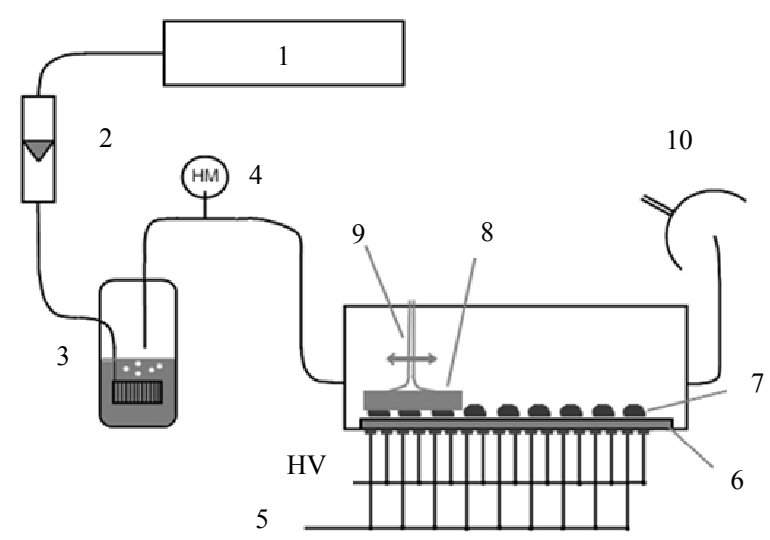

Figure 1. Scheme of experimental setup. 1-air compressor, 2-gas flow meter, 3-bubbler, 4-humidity meter, 5-high voltage $(\sim 12 \mathrm{kV}, \sim 12 \mathrm{kHz}), 6-\mathrm{Al}_{2} \mathrm{O}_{3}$ ceramic, 7-plasma layer, 8-sample, 9-moveable sample holder, 10-gas exhaust. 
was operated at $200 \mathrm{~W}$. The exposed and analyzed area had dimensions of $2 \times 3 \mathrm{~mm}^{2}$. The overview spectra was recorded at pass energy of $200 \mathrm{eV}$ with spectral resolution of $1 \mathrm{eV}$, while the high-resolution XPS spectra were recorded at pass energy of $40 \mathrm{eV}$ with an energy resolution of $0.1 \mathrm{eV}$. The $\mathrm{C} 1 \mathrm{~s}$ peak at $285 \mathrm{eV}$ has been used for binding energy calibration. A Shirley-type background was subtracted from all spectra prior to processing of measured data. Binding energies and peak fitting routines were performed by CasaXPS software.

\section{Results}

\subsection{Surface Wettability}

Significant increase of the surface free energy measured on chromium surfaces after the DCSBD plasma treatment was observed. It was found that air humidity has no major influence on the surface wettability. A change of the surface free energy as a function of the treatment time for both dry (relative humidity less than $2 \%$ ) and wet air (relative humidity is more than $90 \%$ ) is shown in Figure 2. Here and in next figures the total height of bars represents total surface free energy, its white parts corresponds to dispersive component and light gray parts corresponds to polar component.

Based on the obtained results of surface wettability it was decided to use the treatment duration of $40 \mathrm{~s}$, because of two main reasons: the value of the SFE reached the saturation region and (based on our preliminary work) the treatment of more than few tenth of seconds' leads to homogeneous surface treatment.

The increase of hydrophilicity after the water immersion was observed. The procedure of water immersion was done in the next way. The samples were stored in deionized water for definite time; then they were carefully dried by flow of compressed dry air and kept in air for $5 \mathrm{~min}$ before the wettability measurements. It was found that plasma treatment significantly enhance the hydrophilic increase. Figure 3 depicts the changes of the SFE for samples treated in nitrogen, oxygen, dry air and wet air prior to water immersions. The annotations on the $\mathrm{x}$-axis should be read as follows: " $2 \mathrm{~d}$ water" means that immediately after treatment samples were stored in deionized water for 2 days, " $2 \mathrm{~d}$ water, $5 \mathrm{~d}$ dry air" meaning that after treatment and 2 days of storage in water, the samples were kept for additional 5 days in dry air. The samples treated in air were processed by inverse procedure (first storage in air, then immersion in water), because the water immersion didn't lead to further wettability increase.

To examine the aging effect, additional series of measurements were done on the samples treated in dry/wet air, nitrogen and oxygen with further aging in

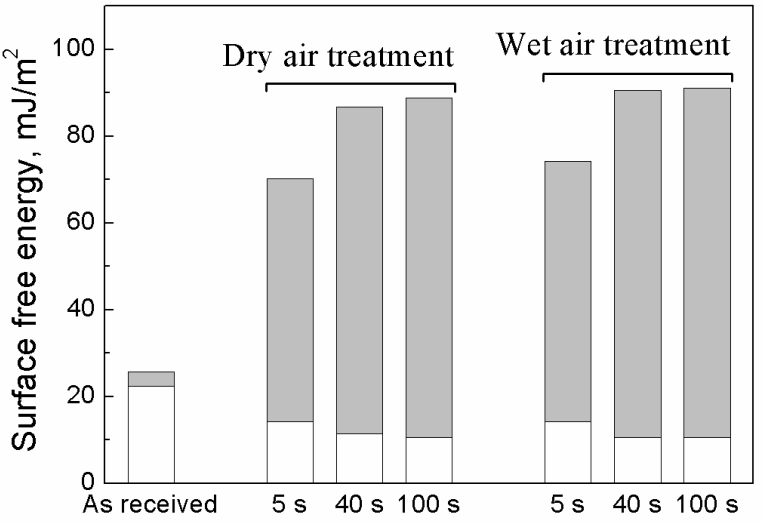

Figure 2. The SFE of chromium surfaces (total bar height) after the DCSBD plasma treatment in dry and wet air. White parts correspond to dispersive component; gray parts correspond to polar component.

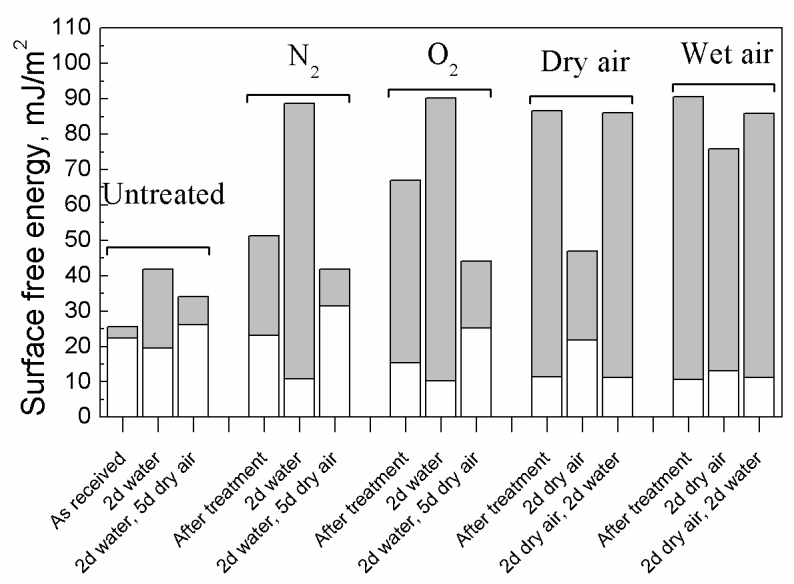

Figure 3. Increase of hydrophilicity after water immersion for chromium surfaces treated in different gases for $40 \mathrm{~s}$.

ambient air. To ensure the aging process is finished it was decided to store samples for 2 days (based on the measurements for few metal substrates using the coplanar plasma source). Storage in dry air was done in exicator with zeolite (room temperature, humidity not more than $10 \% \mathrm{RH})$. Storage in wet air was performed in a closed and partially filled by deionized water box (room temperature, humidity more than $80 \% \mathrm{RH}$ ). The results of these measurements are presented in Figures 4(a)-(d) for plasma treatment in wet air, dry air, nitrogen and oxygen, respectively.

The following features were observed.

- Surface wettability increased for plasma treatment in different gases in the following order: nitrogen $<$ oxygen $<$ dry air $<$ wet air.

- The aging effect is more strong (surface become more hydrophobic) in dry air, while storing samples in wet air after the plasma treatment in nitrogen and oxygen leads to wettability improvement. 


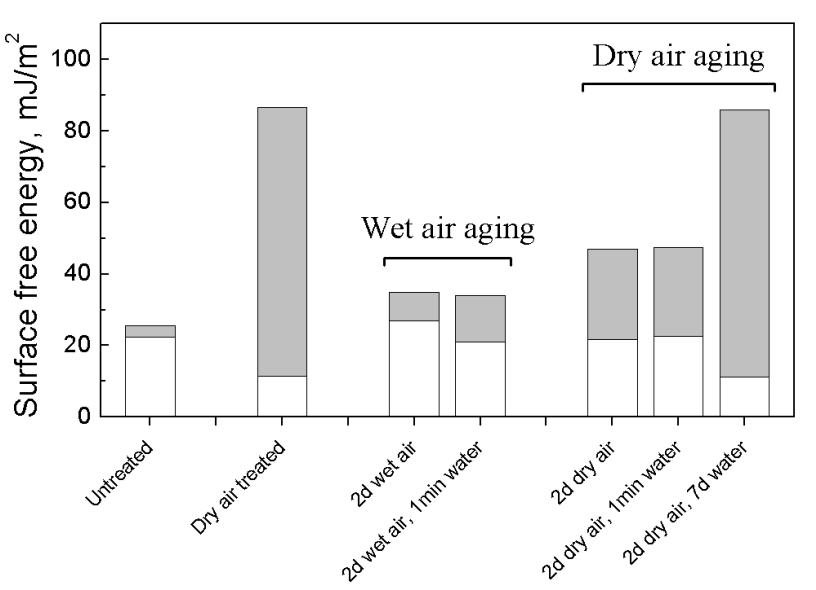

(a)

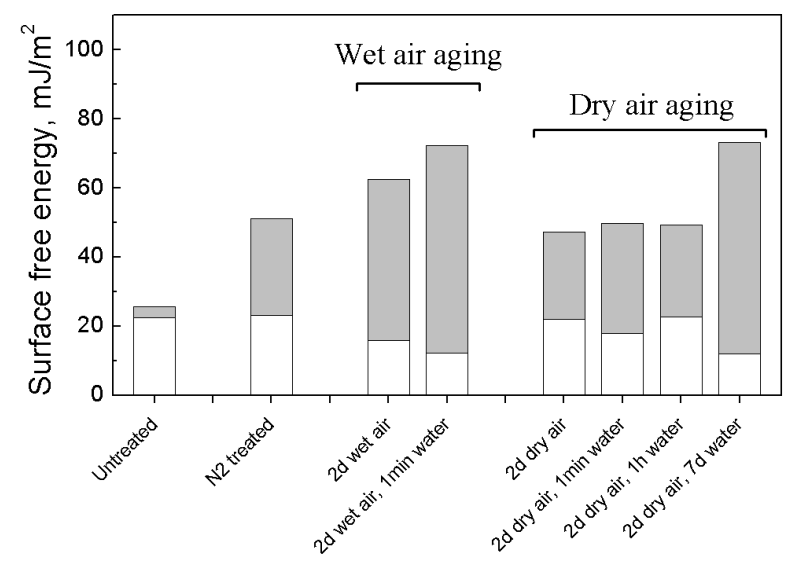

(c)

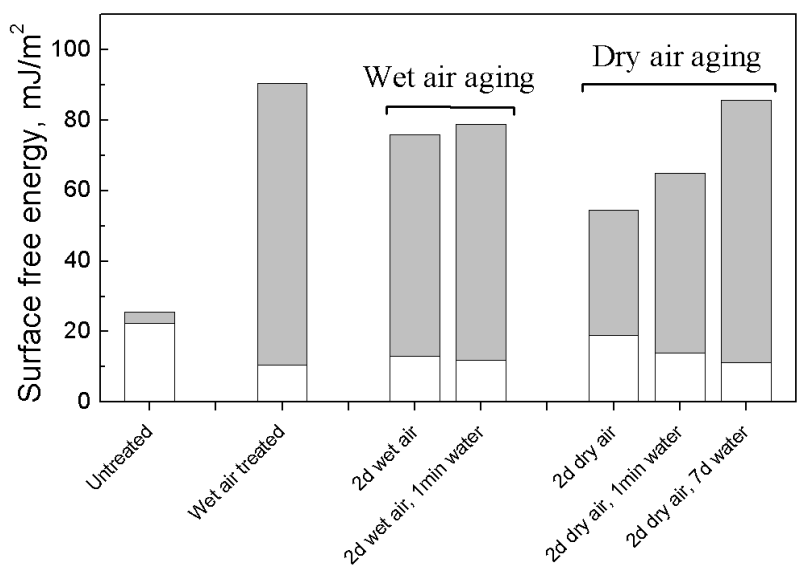

(b)

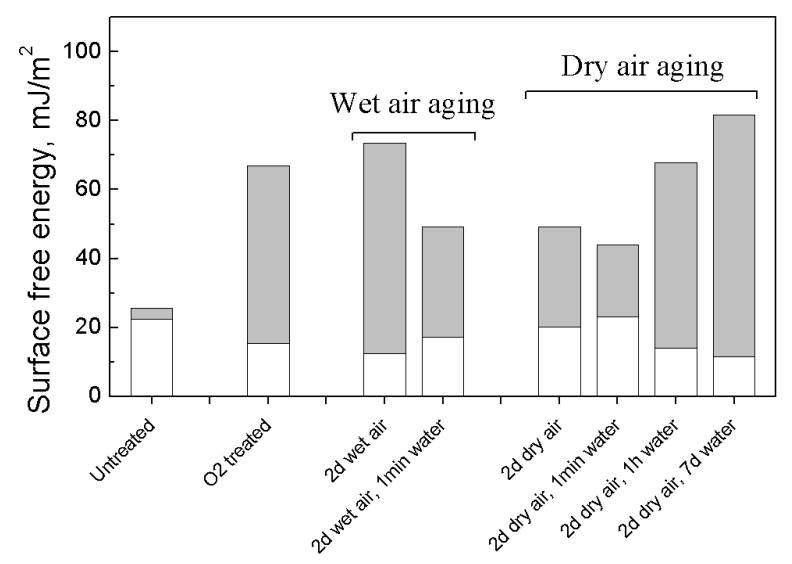

(d)

Figure 4. The changes of surface wettability after different sample storage: (a) Plasma treatment in wet air; (b) Plasma treatment in dry air; (c) Plasma treatment in nitrogen and (d) Plasma treatment in oxygen.

- Water immersion leads to the increase of the surface wettability not immediately. The reasons will be described in Discussion section.

- Immersion in water leads to growth of polar component of the SFE.

\subsection{Changes in Elemental Composition and Bond Structure}

The results of elemental composition depending on treatment gas are presented in Tables 1-3 for the plasma treatment in air, nitrogen and oxygen, respectively. The presented data are divided into two parts. Upper rows contain the elemental composition of chromium surface measured immediately (a time delay of $30 \mathrm{~min}$ to introduce the sample in vacuum chamber) after the plasma treatment for $5 \mathrm{~s}$ and $40 \mathrm{~s}$. Last two rows in each table show the elemental composition of samples treated for $40 \mathrm{~s}$ and further stored in vacuum ("Vacuum, 4d") or ambient air ("Air, $4 \mathrm{~d}$ ") for duration of 4 days.
Few systematic changes in the elemental composition after the plasma treatment were observed.

1) The plasma treatment resulted in the surface cleaning. The cleaning effect can be supported by following the changes of the carbon content (cleaning means it is decreasing). The increase of treatment time corresponds to more pronounced decrease of the carbon at the surface.

2) Presence of $\mathrm{Na}, \mathrm{K}$ and $\mathrm{Ca}$ are due to contamination from the chromization procedure, and was shown for the purpose of full representation of experimental results.

3) Increase of atomic oxygen can be due to additional surface oxidation or surface cleaning. It will be briefly discussed later.

4) Aging of the plasma treated chromium surfaces in vacuum resulted in insignificant change of carbon content, while storage in air resulted in slight increase of carbon content.

5) An appearance of N 1s peak in the XPS spectra was observed. The reasons for this will be discussed later. 
Table 1. Surface composition (in atomic \%) of $\mathrm{Cr}$ samples plasma treated in air.

\begin{tabular}{cccccccc}
\hline & $\mathbf{C r}$ & $\mathbf{O}$ & $\mathbf{C}$ & $\mathbf{N}$ & $\mathbf{N a}$ & $\mathbf{K}$ & $\mathbf{C a}$ \\
\hline Reference & 6 & 48 & 40 & 2 & 2 & 1 & 1 \\
5 s, air & 12 & 67 & 13 & 6 & $<1$ & $<1$ & $<1$ \\
40 s, air & 18 & 62 & 11 & 7 & $<1$ & $<1$ & $<1$ \\
Vacuum, 4d & 16 & 64 & 15 & 4 & $<1$ & $<1$ & $<1$ \\
Air, 4d & 1 & 74 & 21 & 1 & $<1$ & $<1$ & $<1$ \\
\hline
\end{tabular}

Table 2. Surface composition of $\mathrm{Cr}$ samples plasma treated in nitrogen.

\begin{tabular}{cccccccc}
\hline & $\mathbf{C r}$ & $\mathbf{O}$ & $\mathbf{C}$ & $\mathbf{N}$ & $\mathbf{N a}$ & $\mathbf{K}$ & $\mathbf{C a}$ \\
\hline Reference & 6 & 48 & 40 & 2 & 2 & 1 & 1 \\
5 s, nitrogen & 16 & 63 & 13 & 1 & 4 & $<1$ & $<1$ \\
40 s, nitrogen & 17 & 65 & 11 & 1 & 5 & $<1$ & $<1$ \\
Vacuum, 4d & 20 & 61 & 11 & 1 & 3 & 1 & 2 \\
Air, 4d & 17 & 61 & 18 & $<1$ & 2 & $<1$ & 1 \\
\hline
\end{tabular}

Table 3. Surface composition of $\mathrm{Cr}$ samples plasma treated in oxygen.

\begin{tabular}{cccccccc}
\hline & Cr & O & C & N & Na & K & Ca \\
\hline Reference & 6 & 48 & 40 & 2 & 2 & 1 & 1 \\
5 s, oxygen & 11 & 65 & 16 & 6 & $<1$ & $<1$ & 1 \\
40 s, oxygen & 17 & 59 & 15 & 6 & 1 & $<1$ & $<1$ \\
Vacuum, 4d & 16 & 60 & 15 & 3 & 4 & 1 & 1 \\
Air, 4d & 17 & 61 & 20 & 1 & 1 & $<1$ & $<1$ \\
\hline
\end{tabular}

\section{Discussion}

The component analysis of the chromium peak $\mathrm{Cr} 2 \mathrm{p}_{3 / 2}$ was done to explain the changes in surface after the plasma treatments with different conditions as well as hydrophobic recovery of the plasma treated surfaces. The peak was fitted by 4 components according to literature [23] (the $\mathrm{Cr} 2 \mathrm{p}_{3 / 2}$ spectra are not presented here; see Table 4). The component at $574.6 \mathrm{eV}$ was attributed to metallic $\mathrm{Cr}$ and it was decreasing after the plasma treatment. Taking in account that the plasma treatment resulted in the surface cleaning (carbon content decreased) and signal from atomic chromium increase, it means that the treatment resulted in additional surface oxidation.

Changes in hydroxide (binding energy $577 \mathrm{eV}$ ), and chromium oxides $\left(\mathrm{CrO}_{3}\right.$ at $576.3 \mathrm{eV}$ and $\mathrm{C}_{2} \mathrm{O}_{3}$ at $\left.576 \mathrm{eV}\right)$ components were carefully studied. The contributions of $\mathrm{Cr}(\mathrm{III})$ oxide, hydroxide and $\mathrm{Cr}(\mathrm{VI})$ oxide measured after
Table 4. Assignment of the $\mathrm{Cr} 2 \mathrm{p}_{3 / 2}$ peak components.

\begin{tabular}{ccc}
\hline Component & Binding energy, eV & FWHM, eV \\
\hline $\mathrm{Cr}$ & 574.6 & 1.8 \\
$\mathrm{CrO}_{3}$ & 576.3 & 2 \\
$\mathrm{Cr}(\mathrm{OH})_{3}$ & 577 & 2.5 \\
$\mathrm{Cr}_{2} \mathrm{O}_{3}$ & 576 & 2 \\
\hline
\end{tabular}

different treatments are shown in Figures 5-7, respectively. The annotation on the figures should understood as follows: mark " $\mathrm{O}_{2}$ plasma" means the dependence was obtained after plasma treatment in oxygen; mark "Aging process" means the data values are referring to the ones measured from the aged samples; "Air, 2d" means the samples were treated for $40 \mathrm{~s}$ and then further stored in ambient air 2 days; "Vacuum, 2d" means the samples were treated for $40 \mathrm{~s}$ and then further stored in vacuum (pressure $10^{-5} \mathrm{~Pa}$ ) for 2 days.

Note that the plasma treatment resulted in decrease of $\mathrm{CrO}_{3}$ oxide and surface hydration (significantly pronounced for air plasma due to presence of air humidity) and formation of $\mathrm{Cr}_{2} \mathrm{O}_{3}$ oxide (significantly pronounced for oxygen plasma due to higher amount of excited and ionized oxygen species).

The trends for aging process were similar for all treatment gases. While storage of the plasma treated surfaces in ambient air there is a slight increase of carbon content on the surface (hydrocarbon re-adsorption), transformation of $\mathrm{Cr}_{2} \mathrm{O}_{3}$ to hydroxide or $\mathrm{CrO}_{3}$. Aging in vacuum resulted in absence of hydrocarbon re-adsorption (that can be expected), decrease of hydroxide component (that is typically the case, as, for example, for aluminium [24]).

Based on the peak analysis results, we are able explaining observed changes of the surface wettability as follows.

1) Marked increase of wettability is due to the surface cleaning and oxide transformation in upper chromium layer. The amount of hydroxide on the surface plays the major role on the surface wettability, which can be seen comparing the surface free energies after air plasma (Figures 4(a) and (b)), compared to oxygen/nitrogen (Figures 4(c) and (d)) with respect to the hydroxide on the surface (Figure 6). The immersion of the treated surfaces in water leads to more pronounced hydration of the oxide layer, therefore, to higher surface wettability.

2) The aging effect of the plasma treated chromium surfaces is mostly due to the transformations in the oxide components, rather than the effect of hydrocarbon re-adsorption like in the case of aluminium or copper, for example. The changes in the wettability are mostly related to the surface hydration, which can be seen by corre 


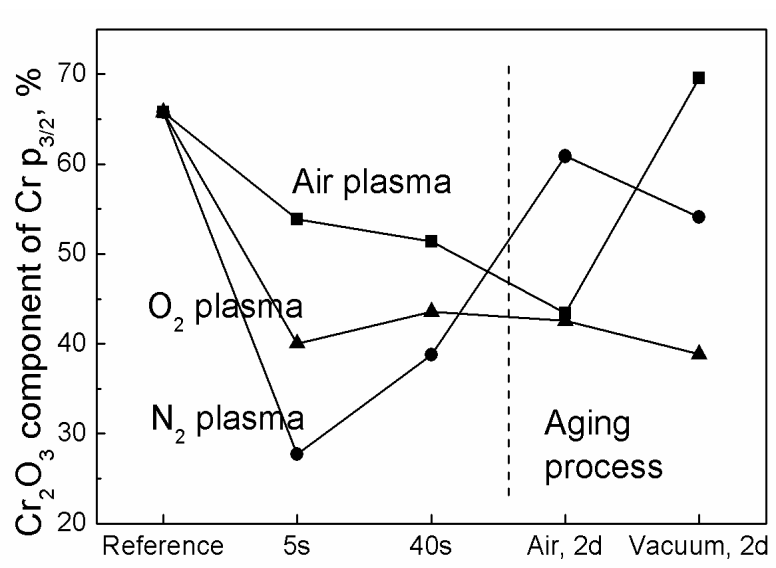

Figure 5. Contribution of $\mathrm{Cr}$ (III) oxide calculated from peak fitting of $\mathrm{Cr} 2 \mathrm{p}_{3 / 2}$ peak depending on treatment and aging conditions.

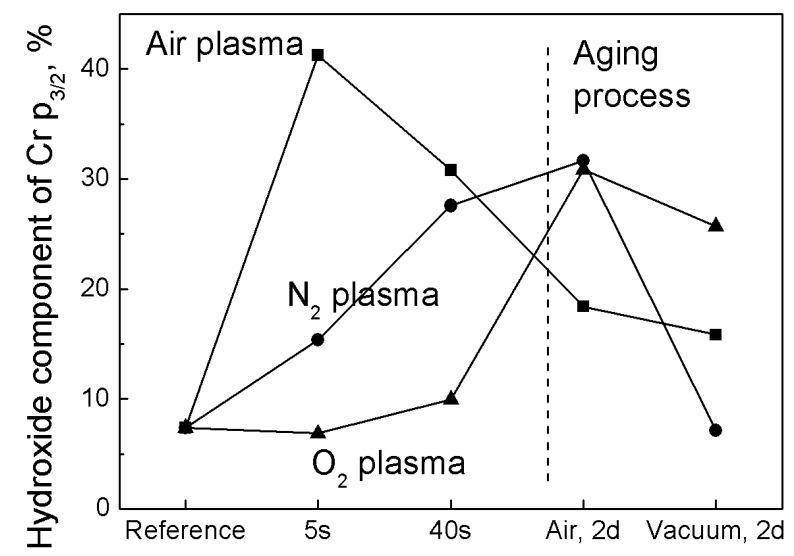

Figure 6. Contribution of chromium hydroxide calculated from peak fitting of $\mathrm{Cr} 2 \mathrm{p}_{3 / 2}$ peak depending on treatment and aging conditions.

lation in between Figures 4(c) and (d) with Figure 6.

Note an appearance of nitrogen in the XPS spectra after the plasma treatments. The $\mathrm{N} 1 \mathrm{~s}$ peak in spectra that one component at binding energy $407 \mathrm{eV}$. By the energy shift this component is can be assigned to $-\mathrm{NO}_{\mathrm{x}}$ groups. We found that presence of nitrate groups are found after non thermal plasma treatments on other metals also. We also observed that the intensity of $\mathrm{N} 1 \mathrm{~s}$ peak is increasing when humidity of air increased. It seems like we can correlate with increase with higher production of nitrate radicals (as intermediate products of more reach plasma chemistry) in the plasma volume [25].

\section{Conclusions}

The effects of plasma gas, air humidity and aging environment on chromium surface plasma treatment were reported. The plasma treatments were done using the specific type of surface barrier discharge (the so-called diffuse coplanar surface barrier discharge), representing

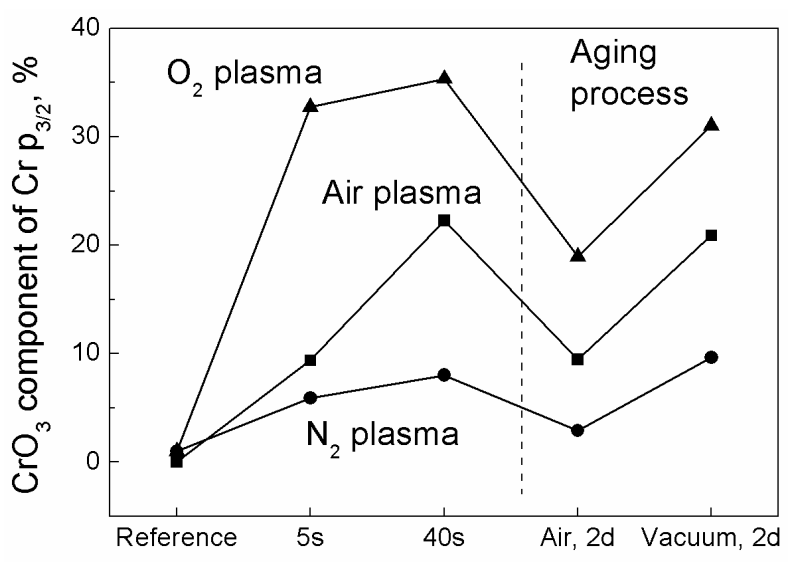

Figure 7. Appearance of $\mathrm{Cr}(\mathrm{VI})$ oxide after the plasma treatment.

one source that produce cold diffuse-like plasma on large flat surface.

The plasma treatment resulted in significant increase of the surface wettability that was estimated by calculating the surface free energy. It was shown that using relatively short exposition time ( $40 \mathrm{~s}$ ), it is possible homogeneously increase the SFE of chromium from $29 \mathrm{~mJ} / \mathrm{m}^{2}$ to over $80 \mathrm{~mJ} / \mathrm{m}^{2}$. The element composition (using quantitative XPS analysis) and chemical bonds (by fitting of $\mathrm{Cr} 2 \mathrm{p}$ peak) were done in order to explain the surface changes after the plasma treatments. From presented results it is apparent that the increase of the surface wettability can be explained by hydration effect and surface cleaning. The hydration of chromium surface plays the major role in the surface wettability. That was additionally proven after immersion of the treated samples in the deionized water, when the wettability was increased as well as amount of surface hydroxides.

The aging effect of the plasma treatment was measured and explained. The hydrophobic recovery of the plasma treated surfaces in related to the dehydration of chromium oxide. However, the generation of $\mathrm{Cr}_{2} \mathrm{O}_{3}$ after the plasma treatment was reported. It might be potentially interesting for many industrial applications, because if beneficial properties of $\mathrm{Cr}_{2} \mathrm{O}_{3}$ as interlayer material.

An observation of nitrate groups on chromium surface after humid air plasma treatment are in agreement with the results obtained on other metallic substrates (aluminium, copper, steel). This result allows us speculating that nitrate groups were attached to the surface from the plasma volume, where they were intermediate products of chemical reactions. The observed nitrate groups are not stable in air, but still their appearance might be interesting for some bio-applications, where metal surface are in the contact with the living tissue that is sensitive to the presence of nitrite functionalities. 


\section{Acknowledgements}

Author thanks to Prof. M. Cernak for providing access to the coplanar plasma source and Mgr. J. Matousek for helping with the XPS measurements.

This research has been partially supported by the Czech Science Foundation (Project No. 104/08/0229) and Ministry of Education, Youth and Sports of Czech Republic (Project No. CZ.1.05/2.1.00/03.0086).

\section{REFERENCES}

[1] PlasmaTreat OpenAir. http://www.plasmatreat.com/plas- ma-technology/

[2] VITO PlasmaSpot. http://www.vitoplasma.com/en/30

[3] Corotec PlasmaJet. http://corotec.com/products/ plasmajet-specs.html

[4] T. Desmet, R. Morent, N. De Geyter, C. Leys, E. Schacht and P. Dubruel, "Nonthermal Plasma Technology as a Versatile Strategy for Polymeric Biomaterials Surface Modification: A Review," Biomacromolecules, Vol. 10, No. 9, 2009, pp. 2351-2378. doi:10.1021/bm900186s

[5] R. Morent, N. De Geyter, J. Verschuren, K. De Clerck, P. Kiekens and C. Leys, "Non-Thermal Plasma Treatment of Textiles," Surface \& Coatings Technology, Vol. 202, No. 14, 2008, pp. 3427-3449. doi:10.1016/j.surfcoat.2007.12.027

[6] M. J. Shenton and G. C. Stevens, "Surface Modification of Polymer Surfaces: Atmospheric Plasma versus Vacuum Plasma Treatments," Journal of Physics D: Applied Physics, Vol. 34, No. 18, 2001, pp. 2761-2768. doi:10.1088/0022-3727/34/18/308

[7] T. Suzuki, Y. Sawado and Y. Fujii, "Oxide Film Formation on Metal Surfaces by Atmospheric Pressure RF Barrier Discharge Plasmas," Plasma Processes and Polymers Vol. 4, 2001, pp. 498-501.

doi:10.1002/ppap.200731214

[8] T. Yamamoto, A. Yoshizaki, T. Kuroki and M. Okubo, "Aluminum Surface Treatment Using Three Different Plasma-Assisted Dry Chemical Processes," IEEE Transactions on Industrial Applications, Vol. 40, No. 5, 2004, pp. 1220-1225.

[9] D. F. O'Kane and K. L. Mittal, "Plasma Cleaning of Metal Surfaces," Journal of Vacuum Science and Technology, Vol. 11, No. 3, 1974, pp. 567-569. doi:10.1116/1.1318069

[10] B. R. Strohmeier, "Improving the Wettability of Aluminum Foil with Oxygen Plasma Treatments," Journal of Adhesion Science Technology, Vol. 6, No. 6, 1992, pp. 703-718. doi:10.1163/156856192X01051

[11] M. Morra, E. Occhiello, R. Marola, F. Garbassi, P. Humphrey and D. Johnson, "On the Aging of Oxygen PlasmaTreated Polydimethylsiloxane Surfaces," Journal of Colloid and Interface Science, Vol. 137, No. 1, 1990, pp. 1124. doi:10.1016/0021-9797(90)90038-P

[12] M. Mantel and J. P. Wightman, "Influence of the Surface Chemistry on the Wettability of Stainless Steel," Surface and Interface Analysis, Vol. 21, No. 9, 1994, pp. 595-605. doi:10.1002/sia.740210902

[13] J. R. Roth, Z. Y. Chen and P. P. Y. Tsai, "Treatment of Metals, Polymer Films, and Fabrics with a One Atmosphere Uniform Glow Discharge Plasma (OAUGDP) for Increased Surface Energy and Directional Etching," Acta Metalugrica Sinica, Vol. 14, No. 6, 2001, pp. 391-407.

[14] C. O'Connell, R. Sherlock, M. D. Ball, B. Aszalos-Kiss, U. Prendergast and T. J. Glynn, "Investigation of the Hydrophobic Recovery of Various Polymeric Biomaterials After 172 nm UV Treatment Using Contact Angle, Surface Free Energy and XPS Measurements," Applied Surface Science, Vol. 255, No. 8, 2009, pp. 4405-4413. doi:10.1016/j.apsusc.2008.11.034

[15] D. H. Shin, C. U. Bang, J. H. Kim, Y. C. Hong, H. S. Uhm, D. K. Park and K. H. Kim, "Treatment of Metal Surface by Atmospheric Microwave Plasma Jet," IEEE Transactions on Plasma Science, Vol. 34, No. 4, 2006, pp. 1241-1246. doi:10.1109/TPS.2006.876486

[16] F. Tochikubo, S. Uchida, H. Yasui and K. Sato, "Numerical Simulation of NO Oxidation in Dielectric Barrier Discharge with Microdischarge Formation," Japanese Journal of Applied Physics, Vol. 48, No. 7, 2009, pp. 076507. doi:10.1143/JJAP.48.076507

[17] K. Iskenderova, A. Chirokov, A. Gutsol, A. Fridman, L. Kennedy, K. D. Sieber, J. M. Grace, K. S. Robinson, "Simulation of $\mathrm{NO}_{\mathrm{x}}$ Formation in Dielectric Barrier Discharge," 15th International Symposium on Plasma Chemistry, Orleans Symposium Proceedings, Vol. II, 2001, pp. 443-448.

[18] M. Černák, L. Černáková, I. Hudec, D. Kováčik and A. Zahoranová, "Diffuse Coplanar Surface Barrier Discharge and Its Applications for In-line Processing of LowAdded-Value Materials," The European Physical Journal Applied Physics, Vol. 47, No. 2, 2009, p. 22806. doi:10.1051/epjap/2009131

[19] M. Černák, J. Ráhel', D. Kováčik, M. Šimor, A. Brablec and P. Slavíček, "Generation of Thin Surface Plasma Layers for Atmospheric-Pressure Surface Treatments," Contributions to Plasma Physics, Vol. 44, No. 5-6, 2004, pp. 492-495. doi:10.1002/ctpp.200410069

[20] D. Y. Kwok and A. W. Neumann, "Contact Angle Measurement and Contact Angle Interpretation," Advances in Colloid and Interface Science, Vol. 81, No. 3, 1999, pp. 167- 249. doi:10.1016/S0001-8686(98)00087-6

[21] Potassium Carbonate Handbook, Technical Data for Potassium Carbonate, Armand Products, Table 10. www.armandproducts.com/pdfs/k2so3P33 46.pdf

[22] A. Rudawska and E. Jacniacka, "Analysis for Determining Surface Free Energy Uncertainty by the Owen-Wendt Method," International Journal of Adhesion and Adhesives, Vol. 29, No. 4, 2009, pp. 451-457. doi:10.1016/i.ijadhadh.2008.09.008

[23] A. M. Salvi, J. E. Castle, J. F. Watts and E. Desimoni, "Peak Fitting of the Chromium 2p XPS Spectrum," Applied Surface Science, Vol. 90, No. 3, 1995, pp. 333-341. doi:10.1016/0169-4332(95)00168-9

[24] A. Nylund and I. Olefjord, "Surface Analysis of Oxidized Aluminium," Surface and Interface Analysis, Vol. 21, No. 
5, 1994, pp. 283-289.

doi:10.1002/sia.740210504

[25] A. C. Gentile and M. J. Kushner, "Reaction Chemistry and Optimization of Plasma Remediation of $\mathrm{N}_{\mathrm{x}} \mathrm{O}_{\mathrm{y}}$ from Gas Streams," Journal of Applied Physics, Vol. 78, No. 3, 1995, pp. 2074-2085. doi:10.1063/1.360185 